\title{
UMA PROPOSTA DE ATIVIDADE DE MRUV A PARTIR DE UM EXPERIMENTO REMOTO FEITO COM LIXO ELETRÔNICO - WEBLAB ITA
}

\author{
Vitor Hugo Migoto de Gouvêa ${ }^{1}$ \\ Douglas Carlos Vilela ${ }^{2}$ \\ Priscila Freitas-Lemes ${ }^{3,4}$ \\ Gilberto Vieira Mendes ${ }^{5}$ \\ José Silvéro Edmundo Germano ${ }^{6}$
}

Resumo: Há alguns anos a tecnologia vem remodelando a natureza dos laboratórios, principalmente com o desenvolvimento dos Laboratórios Controlados Remotamente, chamados de WebLabs. WebLabs são ambientes que permitem interagir, controlar, monitorar e analisar os dados de experimentos remotamente, através da Internet. São semelhantes às técnicas de simulação, porém, permite ao aluno trabalhar com dados reais, além de otimizar espaço, tempo e custo perante um laboratório tradicional. Com o intuito de melhorar a aprendizagem de física, este trabalho apresenta uma proposta de estudo do Movimento Retilíneo Uniformemente Variável (MRUV) por meio de um experimento físico construído a partir de lixo eletrônico reciclável com acesso remoto. Atualmente o Lixo Eletrônico está presente em diversos lugares, e o seu descarte ainda é difícil. A vista que esse lixo é composto de motores, sensores e demais componentes, usamos esse material para confeccionar o experimento. A obtenção dos dados e a análise foi feita usando os softwares Mathematica® e Tracker ${ }^{\circledR}$.

Palavras-chave: WebLab; Cinemática; Lixo Eletrônico; Arduino; Tracker®.

\footnotetext{
${ }^{1}$ Física/ITA, Brasil. E-mail: vitormigoto@gmail.com.

${ }^{2}$ Física/ITA, Brasil. E-mail: douglascarlosvilela@gmail.com.

3 Física/ITA, Brasil. E-mail: piprisc@gmail.com.

${ }^{4}$ FEAU/Univap, Brasil. E-mail: priscila@univap.br.

5 Física/ITA, Brasil. E-mail: artecomreciclavel@gmail.com.

${ }^{6}$ Física/ITA, Brasil. E-mail: silverio@ita.br.
} 